\title{
LA PROPIEDAD LITERARIA DE LAS OBRAS DE GUSTAVO ADOLFO BÉCQUER*
}

\author{
FELIPE MÉNGUEZ RodRÍGUEZ
}

\section{RESUMEN}

Mencionamos aquí un contrato editorial entre el editor madrileño Fernando Fe y la viuda de Bécquer, Casta Esteban y Navarro, que corrige las afirmaciones realizadas por Julia Bécquer sobre la propiedad literaria de las obras de su tío. El artículo muestra también la evolución posterior de esta propiedad.

Palabras clave: Bécquer, Casta Esteban, propiedad literaria, contratos editoriales, López Bernagosi, Fernando Fe, Historia de la Edición en el siglo XIX.

\section{LITERARY PROPERTY OF THE WORKS BY GUSTAVO ADOLFO BÉCQUER}

\begin{abstract}
We mention here a publishing contract between the publisher from Madrid Fernando Fe and Bécquer's widow, Casta Esteban y Navarro, which revises the statements pronounced by Julia Bécquer about the literary property of her uncle's works. The article also shows the later evolution of this property.
\end{abstract}

Key words: Bécquer, Casta Esteban, Literary property, Edition contracts, López Bernagosi, Fernando Fe, Publishing history in the nineteenth century.

Dos días después del fallecimiento de Gustavo Adolfo Bécquer, ocurrido en Madrid el 22 de diciembre de 1870, un grupo de fieles amigos del poeta se reunía en el estudio del pintor Casado de Alisal, situado en el número nueve de la Plaza del Progreso, para planear la colección y publicación de sus obras, como forma de rendir un sentido homenaje a la memoria del amigo muerto. A la reunión asistieron, entre otros, los escritores Ramón Rodríguez Correa, Augusto Ferrán, Narciso Campillo y Julio Nombela, el cual nos recuerda en sus memorias que se produjo también la

\footnotetext{
* Este trabajo se ha realizado en el marco del Proyecto I+D+i del MEC: HUM 200763608/FILO.
} 
inesperada visita de Manuel Silvela, a la sazón Ministro de Estado, que ofreció su cooperación a los presentes. Nombela explicita asimismo las resoluciones allí tomadas:

Los que asistimos a la reunión acordamos contribuir con mil reales cada uno a la realización del pensamiento que nos había congregado, abrir para el mismo fin suscripciones en la redacción de La Ilustración de Madrid y en el estudio de Casado del Alisal, costear la impresión de las obras y entregar el dinero que sobrase, que seguramente sobraría, a la viuda y los huérfanos de Bécquer. Una comisión se encargó de buscar en los periódicos en que había escrito sus poesías, leyendas, críticas y demás trabajos literarios; el proyecto se realizó pronto con verdadero amor y acierto; la edición, convenientemente anunciada en los periódicos, se vendió en poco tiempo y la gloria de Bécquer se consolidó ${ }^{1}$.

El éxito de esta edición, aparecida en dos tomos en 1871, fue efectivamente notable, aunque su venta discurrió de forma más lenta de lo que parece sugerir Nombela, hasta agotarse en 1876. Al año siguiente aparecía una segunda edición, también en dos volúmenes, que presentaba no obstante algunas adiciones ${ }^{2}$. El encargado de la publicación era el editor Fernando $\mathrm{Fe}$, en una de sus primeras actuaciones en el oficio, pues tan sólo hacía un año que había tomado la sucesión de Alfonso Durán en su librería de la madrileña Carrera de San Jerónimo. Fernando Fe habría adquirido los derechos correspondientes de la viuda del autor, doña Casta Esteban, y aunque Julio Nombela ha señalado que esa cesión de derechos se produjo por «una cantidad equitativa», tradicionalmente se ha venido prestando atención aquí al testimonio de Julia Bécquer, quien manifestó que el editor madrileño había comprado las obras del poeta a su hijo mayor, Gustavo, cifrando el valor de la transacción en la mísera cantidad de 75 pesetas $^{3}$, las cuales, desde luego, no podían ser un remedio duradero para las estrecheces económicas que, al parecer, sufría la familia.

Muchos han sido los autores que han recogido las palabras de la sobrina del escritor, pero quizás quien ha plasmado de forma más efectista el

${ }^{1}$ NOMBELA, Julio. Impresiones y recuerdos. Madrid: Ed. Tebas, 1976, p.787.

${ }^{2}$ Las adiciones eran: «Cartas literarias a una mujer» y «El prólogo a La Soledad de Augusto Ferrán». Vid. SCHNEIDER, Franz. «Tablas cronológicas de las obras de Gustavo Adolfo Bécquer». Revista de Filología Española, 1929, XVI, p. 391: «Ambos artículos se sacaron con poco trabajo de El Contemporáneo; se insertaron en las Obras antes de las «Rimas», tomo II. Se cambió un tanto el orden de la primera edición.»

${ }^{3}$ BÉCQUER, Julia. «La verdad sobre los hermanos Bécquer. Memorias de Julia Bécquer». Revista de la Biblioteca, Archivo y Museo del Ayuntamiento de Madrid, 1932, n. ${ }^{\circ} 33$, p. 91. Se hacen eco de esta noticia, entre otros, CARPINTERO, Heliodoro. Bécquer, de par en par. Madrid: Ínsula, 1971, p. 134; MARTÍNEZ CACHERO, José María. «La viuda de Bécquer, escritora». Studia Philologica: Homenaje a Dámaso Alonso. Madrid: Gredos, 1961, tomo II, p. 448; RIZOS JIMÉNEZ, Carlos Ángel. «Mi primer ensayo, de Casta Esteban». El Gnomo. Boletín de estudios Becquerianos, 1997, n. ${ }^{\circ}$ 6, p. 118 . Hasta hoy, que nosotros sepamos, nadie ha desmentido este dato. 
estado de la cuestión ha sido Rafael Montesinos, el cual, glosando el destino del manuscrito de Bécquer conocido como Libro de los gorriones, recordaba que en 1896 había sido vendido por una desconocida Consuelo B. de Ortiz a la Biblioteca Nacional, y el hecho de que la venta se efectuase por 25 pesetas, le daba pie a Montesinos para realizar la breve reflexión siguiente, encabezada con este colorista epígrafe, «Los veinte duros de Bécquer»:

\begin{abstract}
Acabamos de decir que el Libro de los gorriones costó veinticinco pesetas. Mucho tiempo antes, el editor Fernando Fe compró al hijo mayor de Bécquer los derechos de autor por quince duros. Y aún se quejaba el susodicho editor —en carta inédita que conservo en mi archivo- de que los familiares del gran poeta sevillano no le habían entregado el prometido manuscrito de las Rimas. Es decir, que entre las veinticinco pesetas de 1896 y las setenta y cinco del señor Fe, las obras completas de Bécquer (autógrafos incluidos) costaron exactamente cien pesetas: ese mismo billete que un siglo después reproduciría millones de veces la efigie de Gustavo Adolfo Bécquer, no sabemos si como homenaje o como remordimiento ${ }^{4}$.
\end{abstract}

\title{
UN CONTRATO EDITORIAL ENTRE FERNANDO FE Y CASTA ESTEBAN Y NAVARRO
}

No nos atrevemos a negar taxativamente - aunque en realidad lo dudamos mucho-, que hubiese existido en efecto una cesión de los trabajos literarios de Bécquer llevada a cabo por la cantidad que apunta su sobrina, doña Julia, pero sí estamos en condiciones de afirmar que esa cesión, fuese cual fuese su precio, no fue en modo alguno absoluta, y se limitó muy posiblemente a la segunda edición de las Obras. En nuestra opinión, en el periodo comprendido entre 1877 y 1885 , cada nueva edición que salía a la calle bajo el sello de Fernando Fe (fueron tres en total durante ese intervalo) iba precedida de su correspondiente contrato (o de un acuerdo privado, al menos) y del abono por parte del editor de los derechos estipulados.

Así debió suceder también, aunque no tenemos constancia documental de ello, con la tercera aparición de las $\operatorname{Obras}^{5}$, puesta a la venta en dos tomos en 1881. Sí disponemos, en cambio - y es la fuente principal en la que nos basamos para avalar nuestra hipótesis ${ }^{6}-$, del contrato de edición

${ }^{4}$ MONTESINOS, Rafael. La semana pasada murió Bécquer. Madrid: Ed. 2000 S.A., 1984, p. 10. Este volumen acompaña la edición facsímil del manuscrito bécqueriano Libro de los gorriones, realizada en esta misma fecha por la citada editorial.

${ }^{5}$ En esta ocasión se añadieron las composiciones «Roncesvalles» y «Las dos olas», amén de algunos cambios en el orden. SCHNEIDER, Franz, op. cit., p. 391.

${ }^{6}$ Existe, sin embargo, otra declaración que corrobora nuestro planteamiento. Jorge Bécquer, en documento notarial sobre el que volveremos más adelante, manifestaba que de las obras de su padre no se había transmitido otro derecho que el de imprimirlas y publicarlas en cuatro ediciones. 
firmado el 20 de agosto de 1884 entre el editor y librero Fernando Fe y la viuda del autor, doña Casta Esteban y Navarro?

En este documento, Casta manifestaba personarse, además de por su propio derecho, como madre y representante legal, en el ejercicio de la patria potestad de sus hijos menores de edad Gustavo y Jorge Bécquer y Esteban ${ }^{8}$. Asimismo, declaraba que como viuda de Gustavo Adolfo Bécquer era plena propietaria de una mitad de las obras en prosa y verso de su difunto esposo, en calidad de bienes gananciales. De la otra mitad, una tercera parte le correspondía también como única heredera de su hijo Emilio Bécquer y Esteban, que había fallecido en $1878^{9}$. Y las otras dos terceras partes de esa mitad correspondían a sus otros dos hijos, Jorge y Gustavo $^{10}$.

Según los términos del contrato, Casta Esteban cedía «sin reserva ni limitación alguna, todos sus derechos a publicar y vender una nueva edición, que será la cuarta, de la colección de trabajos literarios de su difunto marido, conocida con el nombre de Obras de Bécquer. Se estipulaba que se utilizaría el mismo papel y forma que en la tercera edición, aunque el tipo de letra podría ser mayor, llegando a conformar tres tomos, y tasando el precio de cada ejemplar en un máximo de once pesetas, aunque el señor Fernando Fe podía, sin rebasar ese máximo, marcar el precio que estimase más conveniente. La tirada quedaba fijada en cuatro mil ejemplares.

Se indicaba también que se incluirían todas las producciones de Bécquer ya publicadas en las ediciones anteriores y, además, «las que el señor Fe crea conveniente insertar de las que la Señora Doña Casta Esteban le ha entregado como inéditas de su finado esposo, y un prólogo del Señor Segovia Rocaberti, que también le ha entregado, si el Señor Fe estimase

${ }^{7}$ Este contrato se celebró ante el notario Félix González Carballeda, y se halla en el Archivo Histórico de Protocolos Notariales de Madrid (AHPN), protocolo 35.232, folios 4.167 a 4.176. Todos los entrecomillados son transcripción directa del mismo, limitándonos, simplemente, a adaptar la ortografía a los usos actuales.

${ }^{8}$ Aunque Gustavo Adolfo, el hijo mayor, tenía en esos momentos veintidós años, en la época no se alcanzaba la mayoría de edad hasta cumplidos los veinticinco, teniendo el padre, o en su defecto la madre, potestad sobre sus hijos legítimos no emancipados. Artículos 205 y 206 del Código Civil entonces vigente.

${ }^{9}$ Curiosamente, Carpintero, el biógrafo que más se ha interesado en indagar en la vida de los hijos de Bécquer, nos dice de Emilio que «de él no hay más datos concretos que el de su nacimiento [15/12/1868]. Y la certeza de que no murió de corta edad, ya que han sido revisados detenidamente los archivos parroquiales de las localidades en las que lógicamente pudo estar». Y lo califica luego de «tan inmaterial, tan etéreo, que no ha dejado en el mundo una sola huella de su paso.» CARPINTERO, Heliodoro, op. cit., pp. 170-171.

${ }^{10}$ Dado que Gustavo Adolfo Bécquer falleció sin otorgar testamento, es de suponer que este reparto de bienes corresponde a la resolución de algún auto judicial que, por el momento, desconocemos. 
oportuna su inserción». En caso contrario, el editor se obligaba a devolver a la viuda todo el material inédito que no utilizase ${ }^{11}$.

A su vez, doña Casta Esteban se obligaba "por sí y por sus hijos a no ceder ni autorizar ni hacer por sí otra edición de las mismas obras, aunque fuere suprimiendo o adicionando producciones del Señor Don Gustavo Adolfo Bécquer, o coleccionadas en ninguna forma», mientras la nueva publicación de Fernando Fe no estuviese agotada. De incumplirse esta condición, el contrato sería considerado nulo, y Casta debería reintegrar al editor el dinero de la transacción, más una suma adicional en concepto de daños y perjuicios. A estos efectos, se consideraría agotada la edición cuando Fernando Fe no tuviese a la venta del público en su librería de Madrid, ni siquiera dos ejemplares, en rústica, de las mencionadas Obras.

En el mismo documento, se cedía también al editor madrileño el derecho de coleccionar y publicar separadamente, en un tomo, las composiciones conocidas con el nombre de Rimas, pudiendo incluirse en él, si se ajustaban al caso, algunos de los inéditos aportados ahora por la viuda. La tirada establecida era también de cuatro mil ejemplares, quedando el formato y el precio de los mismos a la libre disposición del adquiriente ${ }^{12}$.

Por último, Casta Esteban cedía también a Fernando Fe, «como mandatario que asegura ser de los señores Fermín Didot y Compañía, de París, el derecho para que estos traduzcan al idioma francés y publiquen en una edición de quinientos ejemplares, las Leyendas en prosa» de Gustavo Adolfo Bécquer. Aquí también Casta se obligaba, mientras no se agotara la tirada, a «no publicar ni conceder a ninguna casa nacional o extranjera, el derecho de dar a la estampa en dicho idioma las precitadas Leyendas en prosa, bajo pena de nulidad de este contrato y resarcimiento, a los Señores Didot y Compañía, de daños y perjuicios ${ }^{13}$.

${ }^{11}$ Finalmente las adiciones fueron: «El castillo real de Olite», «Los dos compadres», «A Casta», «El Carnaval», «Poesía inédita», «Amor eterno» y «La noche de difuntos». Consultado el primer volumen en la Biblioteca Nacional, no figura el prólogo de Segovia Rocaberti. En nota a pie de página se indica: «Hemos conservado en esta edición el Prólogo de las anteriores, debido a la pluma de nuestro querido amigo don Ramón Rodríguez Correa, porque además de las noticias referentes a la vida del autor, da de sus obras una idea que juzgamos oportuno reproducir en este lugar.» Si la información que nos da Montesinos es correcta, había un hecho decisivo que jugaba en contra del prólogo del señor Rocaberti, y es este: hasta 1885 «todas las ediciones de Fernando Fe estuvieron a cargo de Ramón Rodríguez Correa». MONTESINOS, Rafael. La semana pasada murió Bécquer, op. cit., p. 40. El malogrado poeta Segovia Rocaberti no parece que se tomara a mal su exclusión: en 1887 el propio Fernando Fe le publicaba su obra Catálogo humorístico en verso de la Exposición de Bellas Artes.

${ }^{12}$ Se explicitó que, aun quedando ejemplares de las Rimas, el contrato se consideraría cumplido y la cuarta edición agotada cuando no quedasen a la venta ejemplares de las Obras en la librería de Fernando Fe. En todo caso, parece ser que este tomo no llegó a publicarse. Nosotros, al menos, no hemos podido encontrar referencias del mismo.

${ }^{13}$ La casa «Firmin-Didot et Cie» publicó el libro - titulado Légendes espagnoles- en París en 1885, con traducción de Achille Fouquier y dibujos de Santiago Arcos Megalde. 
El precio total de estas cesiones se fijó en 5.000 pesetas, desglosadas de este modo:

- 3.000 pesetas por la cuarta edición de las Obras de Gustavo Adolfo Bécquer.

- 1.000 pesetas por la edición especial de las Rimas.

- 1.000 pesetas por la traducción y publicación en francés de las Leyendas.

A Casta Esteban le correspondían «por mitad de gananciales» 2.500 pesetas, y como única heredera de su finado hijo Emilio, un tercio de la otra mitad: 833,33 pesetas, «despreciando, por insignificante una fracción centesimal». La suma total, por tanto, ascendía a 3.333,33 pesetas, mientras que la cantidad restante, $1.666,67$ pesetas, correspondía por iguales partes y pro indiviso a sus dos hijos, Gustavo y Jorge Bécquer y Esteban, «por sus derechos hereditarios».

El pago del precio convenido se realiza de la siguiente forma: Casta «declara y confiesa solemnemente tener recibidas, antes de este acto, del Señor Fernando Fe y Gámez para urgentes atenciones suyas y de la familia, 455 pesetas», y recibe ahora, durante la formalización del contrato y según atestigua el notario, las 2.878,33 pesetas restantes, «en diferentes billetes del Banco de España y monedas de plata y calderilla, que recibe y acepta como efectivo metálico después de haberlas examinado y contado a su satisfacción» ${ }^{14}$.

Un tanto truculento resulta, en cambio, el destino de la cantidad correspondiente a sus vástagos. Doña Casta confiesa que «en atención a las diferencias surgidas entre ella y sus hijos, que no son del caso explicar, y para que éstos siempre vean el cuidado y escrupulosidad con que procede en lo que a sus intereses toca», consiente en que las $1.666,67$ pesetas que les corresponden queden en poder del señor Fernando Fe, para que las

Sería muy interesante profundizar en la relación comercial de ambas empresas editoriales, mas por el momento no hemos podido encontrar fuentes documentales pertinentes. Por otro lado, según Carpintero, en 1883 ya se había producido una primera traducción de las $L e$ yendas al francés. Después aparecerían traducciones de las Rimas en alemán e inglés. Vid. CARPINTERO, Heliodoro, op. cit., p. 221. Rodríguez Correa apuntaba también en su prólogo que «apenas hay lengua culta donde no se hayan traducido sus poesías o su prosa». ¿Pudo tener Casta en las traducciones una fuente adicional de ingresos?

${ }^{14}$ Ateniéndonos a esta información, consignada en documento notarial, debemos concluir que no son ciertas afirmaciones como la ya citada de Rafael Montesinos o, por poner simplemente otro ejemplo, la expresada por Carlos Ángel Rizos: «Con todo, es cierto que Casta sólo se vio remunerada con la primera edición de las Obras de Gustavo (1871), cuyos derechos vendió su hijo Gustavo al librero Fernando Fe por setenta y cinco míseras pesetas». RIZOS JIMÉNEZ, Carlos Ángel, op. cit., p. 118. El error proviene de seguir fielmente el testimonio de Julia Bécquer que, como creemos que se está demostrando aquí, en este punto se ajusta bastante poco a los hechos. 
mantenga en depósito en su caja, o en las del Banco de España o en la Caja General de Depósitos, como mejor le parezca, con la obligación «ineludible y estricta» de entregar esa cantidad, sin interés alguno sea cual sea el tiempo transcurrido, cuando los hijos lleguen a su mayoría de edad, «o se la reclamen habilitados en forma de curador ad bona con cargo judicialmente discernido», o bien mediante la propia figura de su madre, «especialmente autorizada para el cobro e inversión de dicha suma por Juez competente».

Siete meses después de la firma del contrato, el 30 de marzo de 1885, tal vez sin llegar a ver esta nueva edición de las obras de su primer marido $^{15}$, Casta Esteban y Navarro fallecía en el Hospital General de Madrid.

\section{LA SITUACIÓN ECONÓMICA DE LA VIUDA DE BÉCQUER}

La información contenida en el documento que acabamos de reseñar, nos tememos que pueda aportar, muy a nuestro pesar, mayor confusión al ya de por sí embrollado asunto de la economía familiar de los Bécquer. Por una parte, Julio Nombela nos informa de que, a la muerte del poeta, no fue necesario que nadie sufragase los gastos del entierro, pues el autor «disfrutaba de una posición desahogada». Además, la edición póstuma de sus Obras, preparada por sus amigos y admiradores, permitió entregar a su esposa e hijos, según Nombela, «importantes recursos» ${ }^{16}$.

Algo después, el 22 de mayo de 1872, Casta contraía segundas nupcias con el asturiano Manuel Rodríguez Bernardo, recaudador de contribuciones,

${ }^{15}$ La edición se inscribió en el Registro General de la Propiedad Intelectual (RPI) el 30 de mayo de 1885, a las tres de la tarde, según consta en el tomo XIV, folio . $^{\circ}$ 212, de este organismo. Cabría suponer que su salida a la venta se produjo en torno a esta fecha o poco tiempo antes, pero no podemos contar con una seguridad absoluta. La tercera edición, por ejemplo, que había aparecido en noviembre de 1881, no fue registrada por Fernando Fe hasta el 24 de octubre de 1882, es decir, once meses más tarde. RPI, libro VIII, folio n. ${ }^{\circ} 140$.

${ }^{16}$ NOMBELA, Julio, op. cit., pp. 786-787. Gamallo Fierros nos ha informado que los ingresos obtenidos con las subscripciones abiertas en Madrid y Sevilla, para esa edición póstuma, ascendieron en total a 27.964 reales, importando los gastos de publicación 22.100 . Fue por tanto la diferencia, 5.864 reales, lo que se entregó a las viudas: Casta Esteban y Winifreda Cogán, viuda de Valeriano Bécquer, y que también participaba en el reparto, pues la idea original había sido publicar las obras de Gustavo conjuntamente con los grabados de su hermano Valeriano. Parece ser que el alto coste de una edición semejante fue lo que hizo aplazar primero y abandonar después esta idea, y por ello aparecieron en solitario los trabajos literarios de Gustavo Adolfo. En todo caso, Winifreda participó en el reparto, se ignora en qué proporción. Además de la suma arriba reseñada, las viudas recibieron también como beneficio las cantidades derivadas de la venta de los dos mil ejemplares de la tirada, a 28 reales los dos tomos en que se agrupó la producción del poeta. Para seguir mucho más detalladamente todo este proceso de ingresos y gastos, consúltese GAMALLO FIERROS, Dionisio. Estudios sobre Bécquer. Zaragoza: Diputación Provincial de Zaragoza, 2006, pp. 233 y ss. 
que moriría asesinado en febrero de 1873. Para Carpintero, la herencia de su segundo marido, unida a la herencia de su padre, Francisco Esteban, médico de cierta fama y respetable fortuna, fallecido en Noviercas en 1876, deberían de haberle proporcionado recursos económicos suficientes ${ }^{17}$.

Y sin embargo, consta documentalmente que, no demasiado tiempo después de estos sucesos, Casta Esteban, enferma, solicitaba ayuda a la Asociación de Escritores y Artistas Españoles, según figura en el Acta de la Junta Directiva celebrada el 28 de diciembre de 1878. En esta Junta se acordó de forma unánime otorgarle un socorro de 500 reales. Además se puso a su disposición un médico, y los farmacéuticos de la Asociación se ofrecieron a proporcionar gratuitamente las medicinas que fuesen necesarias ${ }^{18}$.

Unos meses antes, el 31 de marzo de 1878, una circular firmada por José Zorrilla, Tomás Rodríguez Rubí, Miguel de los Santos Álvarez, Pedro Antonio de Alarcón, Antonio Fernández Grilo y José Salvador de Salvador, había intentado también «cumplir el doble deber de honrar al muerto [Gustavo Adolfo Bécquer] y de auxiliar a su familia, reproduciendo fotográficamente un fiel retrato de aquel y entregando a esta los productos de la edición del mismo» ${ }^{19}$.

Pero estas ayudas parece que no resultaron suficientes para paliar todos los problemas de Casta, pues en el otoño de 1882 marcha a París, provista de varias cartas de recomendación, tratando de que su situación mejore. En la capital francesa, sin embargo, sufrió una fría acogida que la obligó a procurarse los medios de regresar a España ${ }^{20}$. Ideó entonces, en palabras

${ }^{17}$ Vid. CARPINTERO, Heliodoro, op. cit., p. 133: «Fallece aquel día [17/03/1876] su bondadoso y querido padre, don Francisco Esteban. Su partida de defunción declara: «Hizo testamento, se celebró misa de cuerpo presente, novena, cabo de año y cien misas». Señalamos estos pormenores para que se vea hasta que punto es absurda la leyenda de la miseria de Casta Esteban». Las cursivas son nuestras. Carpintero, como veremos, hace hincapié en este mismo sentido en otras páginas de su libro, y secundan sus opiniones estudios posteriores como el de Carlos Ángel Rizos.

${ }^{18}$ También se iniciaron gestiones para que «recobrase el huérfano de Bécquer la plaza de gracia que había perdido en el Colegio de El Escorial por no haber podido satisfacer ciertos derechos». Vid. SÁNCHEZ PALACIOS, Mariano. «Nota sobre la familia Bécquer». Revista de Literatura, 1956, IX, pp. 153-154.

${ }^{19}$ Una reproducción de la carta y de la fotografía de Bécquer a la que en ella se alude, puede verse en MONTESINOS, Rafael. Bécquer. Biografía e imagen. Sevilla: Fundación José Manuel Lara, 2005, pp. 333 y 306 respectivamente. La circular llevaba una nota con esta indicación: «Cada ejemplar vale 50 rs. El repartidor lleva el recibo de su importe y pasará a cobrarlo cuando V. se sirva designarle.»

${ }^{20}$ López Núñez cree que viajó a Francia «cansada de sufrir la miseria». Y apunta que «Castelar fue uno de los que la proporcionaron algunos medios para el viaje, que fue completamente infructuoso. Allí tampoco podía vivir, y gracias a unos cuantos españoles consiguió repatriarse con algún decoro.» Vid. LÓPEZ NÚÑEZ, Juan. Románticos y Bohemios. Madrid: Editorial Ibero-Americana, 1929, p. 194. Carpintero, sin embargo, muy escéptico como hemos dicho con las supuestas necesidades económicas de Casta, tiene otra visión 
de Martínez Cachero, «el último y sorprendente esfuerzo para librarse de la miseria: la publicación en 1884 del volumen $M i$ primer ensayo» ${ }^{21}$.

Así lo declaraba la propia autora en la dedicatoria del mismo, al afirmar que escribía «estas mal trazadas líneas como último recurso para defenderme de la miseria y del hambre», y anunciaba que la edición se realizaba «a fuerza de inmensos sacrificios, privándome hasta de lo más preciso de la vida para atender a los gastos de impresión» ${ }^{22}$. A este respecto es necesario señalar que la obra se inscribió en el Registro General de la Propiedad Intelectual en el segundo trimestre del año 1884, es decir, antes de la firma del contrato con Fernando Fe, y por lo tanto el dinero que el editor le liquidó a Casta no pudo servir para atender a esos gastos de impresión, salvo, quizás, la pequeña suma que le había sido adelantada.

En todo caso, si realmente la autora pretendía sanear su situación económica con las ventas de su libro, revelaba desde luego cierta ingenuidad; con la literatura resultaba muy difícil en aquellos tiempos ganar dinero, máxime si se trataba de una sola obra, con una tirada que se limitaba a mil ejemplares ${ }^{23}$ y con un precio de venta al público de cinco pesetas.

Nos encontramos en definitiva ante dos posturas antagónicas cuyos argumentos, no obstante, parecen igualmente razonables. Para unos, los legados de su padre y su segundo esposo, más los beneficios que, cuando menos, le habría dejado la primera aparición de las Obras de Bécquer, hacen inverosímil la afirmación de que Casta careciera de recursos económicos. Para otros, es un hecho constatado que pidió y obtuvo ayuda de la Asociación de Escritores y Artistas, ayuda que por tanto debió considerarse justificada. Además, esta segunda corriente crítica estima sincera la declaración de intenciones consignada al comienzo de su libro y, por si fuera poco, rumores ha habido incluso sobre la posibilidad de que hubiese acabado sus días ejerciendo la prostitución ${ }^{24}$.

sobre el viaje de ésta a París: «¿Qué pretende encontrar allí? Ni ella misma lo sabe. En el fondo, su anhelo es viajar, moverse, huir de sus recuerdos y de su paisaje; estar lejos de su padrastro, a quien odia, y de su propia madre.» CARPINTERO, Heliodoro, op. cit., p. 136.

${ }^{21}$ MARTÍNEZ CACHERO, José María, op. cit., p. 449.

${ }^{22}$ ESTEBAN Y NAVARRO, Casta. Mi primer ensayo. Colección de cuentos con pretensiones de artículos. Madrid: Manuel G. Hernández, 1884, pp. 5-6. Para Carpintero en el libro «hay simulación y engaño cuando, con tozuda reiteración, nos habla de su pobreza. [...]. Todo esto es una enorme farsa. Casta no ha conocido semejante angustia económica. Casta posee bienestar propio». CARPINTERO, Heliodoro, op. cit., p. 137.

${ }^{23}$ RPI, libro XI, folio n. ${ }^{\circ}$ 370. No hay tal ingenuidad para Carpintero. Según él, Casta sabía de sobra lo poco que producía la literatura. Luego, «editar un libro en tales circunstancias es un lujo. O el medio de dar cínicos «sablazos» con el embeleco de viuda pobre». CARPINTERO, Heliodoro, op. cit., p. 138.

${ }^{24}$ Esta afirmación, poco verosímil para algunos y simple calumnia para otros, se debe a Jaime Suárez quien, en un artículo en La Estafeta Literaria, en mayo de 1944, decía de Casta que «para colmo, murió como prostituta en el Hospital de San Juan de Dios». Citado 
Aparte de estos controvertidos datos, ahora sabemos de manera fehaciente que Casta recibió una remuneración económica por la cuarta edición de las Obras de Bécquer. La suma no fue excesiva, pero ya de por sí bastante mayor de lo que hasta el momento se afirmaba que había recibido por ellas. Y no nos parece muy aventurado suponer que, al no haber cedido nunca de forma absoluta la propiedad de esas Obras, Fernando Fe la hubiese retribuido también, como era legítimo, cuando aparecieron la segunda y tercera edición de los trabajos de Bécquer. Esta información, que parecería alinearse con la opinión de que los recursos económicos de Casta no eran tan precarios como se ha afirmado, no puede ocultar sin embargo que la viuda, en una de las cláusulas del contrato, se ve en la necesidad de declarar que Fernando Fe le ha tenido que adelantar una pequeña cantidad «para urgentes atenciones suyas y de la familia». La situación parece mantenerse todavía en una ambigua zona de sombras. Creemos que sería pertinente una revisión que tratase de arrojar nueva luz sobre este discutido problema.

\section{LA PROPIEDAD DE LAS OBRAS VIAJA A BARCELONA}

En el último cuarto del siglo XIX la Librería Española era sin duda uno de los establecimientos más pujantes del sector en la ciudad de Barcelona. Su propietario, Inocente López Bernagosi, gerundense de ascendencia italiana, había comenzado como dependiente en la Librería Histórica de Lluís Tasso y, en 1855, deseando establecerse por su cuenta, les había comprado la librería a los hermanos Oliveres i Montmany, trasladándola posteriormente, en 1863, a la Rambla del Centro ${ }^{25}$.

Bernagosi comenzó pronto a realizar también labores de editor, sacando a la venta novelas por entregas, pero destacó sobre todo en la creación

en MARTÍNEZ CACHERO, José María, op. cit., p. 449. Sobre este asunto apuntaba José Félix Navarro: «Si su libro fue escrito en 1884 y ella muere al año siguiente — de esto no hay duda - , nos resistimos a creer que quien acude a la pluma para ayudarse pudiera descender al último peldaño moral a que es capaz de llegar una mujer.»Vid. NAVARRO MARTÍN, José Félix. «Contradicción en torno a la esposa de Gustavo Adolfo Bécquer». Archivo Hispalense, 1956, XXIV, n. ${ }^{\circ} 75$, p. 83.

${ }^{25}$ Una reseña muy breve pero interesante de «La Librería Española, de López» puede verse en MiLlá, Ángel. Libreros y bibliófilos barceloneses del siglo XIX. Apuntes para su pequeña historia. Barcelona: Gremio de Libreros de Barcelona, 1956, pp. 29-31. Allí nos dice el autor: «Por la librería López puede decirse que pasaron todas las figuras literarias, artísticas y políticas más populares de la época, lo mismo nacionales que extranjeras, cuando éstas estaban de paso en Barcelona». Y refiere la siguiente anécdota: «Una tarde del 1882, una dama muy enjoyada entró en la librería y pidió una novela francesa. Era la Sarah Bernhardt, que trabajaba en el Teatro Lírico. López propuso que se colocase una artística placa en la tienda que conmemorase el hecho... Roca y Roca, irónico, propuso que en ella se grabara el siguiente texto: «En tal día como hoy/entró la divina Sarah.../Al no hallar lo que pedía/se marchó sin comprar nada». 
de publicaciones periódicas. A su iniciativa se deben, entre otras, $\mathrm{El} \mathrm{Ca}$ ñón Rayado, dedicada a la guerra de África, El Xanguet, Un tros de paper, Lo Noi de la Mare, La Rambla, La Tabola, Las Barras Catalanas, o El Tiburón, que alcanzaron gran éxito y popularidad. Pero sin duda la publicación más trascendente entre todas las que concibió fue La Campana de Gracia, semanario satírico, republicano y anticlerical, en lengua catalana, cuyo primer número apareció en mayo de 1870. Las autoridades gubernativas suspendieron su aparición en 1872, pero Bernagosi, firmemente posicionado en sus convicciones ideológicas - ya durante la Revolución de septiembre de 1868 había formado parte de la Junta Revolucionaria de Barcelona- no se amilanó. Contestó a la prohibición sacando a la calle un nuevo semanario, L'Esquella de la Torratxa, con el mismo formato y los mismos redactores. Ambas publicaciones se vieron sometidas a varias interrupciones, dictadas por las autoridades, pero superaron siempre las dificultades y llegaron a alcanzar más de sesenta años de vida ${ }^{26}$. Acorde con este compromiso ideológico, Bernagosi publicó también una colección de novelas políticas y, ya en los últimos años de su vida, creó la Colección Diamante, que continuaría su hijo Antonio López con gran éxito, y donde aparecerían autores como Ramón de Campoamor, Pérez Galdós, Pardo Bazán, Blasco Ibáñez, Pérez Escrich, José Zahonero y un largo etcétera.

Ignoramos cómo pudo Jorge Bécquer, hijo del poeta sevillano, entrar en contacto con el republicano editor catalán, pero lo cierto es que el 31 de enero de 1890 ambos acuden ante el notario de Barcelona don Eusebio Thos y Boushoms, y allí Jorge Bécquer y Esteban vende:

A perpetuidad a Don Inocente López Bernagosi la propiedad absoluta y el derecho de reproducción ilimitado de todas las obras literarias en prosa o verso escritas por Don Gustavo Adolfo Bécquer Bastida, lo mismo de las publicadas hasta la fecha de la citada escritura por distintas personas, que las inéditas que pudieran aparecer manuscritas en lo sucesivo, que de todos los artículos, poesías y producciones literarias en general que hubieren visto luz [en] colecciones o sueltas en diferentes periódicos, revistas o ilustraciones ${ }^{27}$.

El editor barcelonés se hacía así con la propiedad de las obras de Bécquer no sólo para España, sino también para las «provincias ultramarinas» y para el extranjero. El precio de la venta se fijó en 6.750 pesetas, de las

${ }^{26}$ Una muy interesante información de todas estas publicaciones, y de la saga de editores fundada por López Bernagosi, puede encontrarse en LLETGET LÓPEZ, Isabel. «Memòries de la familia Lletget López del 1872 al 1942» [en línea]. Biblio 3W. Revista bibliográfica de Geografía y Ciencias Sociales, 2007, XII, n. ${ }^{\circ}$ 697-n. ${ }^{\circ}$ 770. Recurso electrónico disponible en: http://www.ub.es/geocrit/b3w-718.pdf [consultado en marzo de 2008]. La autora es bisnieta del editor. También puede verse una muestra de la labor editorial de López Bernagosi en LLANAS, Manuel. L'edició a Catalunya: el segle XIX. Barcelona: Gremi d'editors de Catalunya, 2004, pp. 161-165.

${ }^{27}$ AHPN, protocolo 37.435. 
cuales el vendedor obtuvo sólo por el momento 750, mientras que las restantes 6.000 le serían entregadas tan pronto como el comprador viese registrado y reconocido en el Registro de la Propiedad Intelectual el derecho que en el mencionado contrato adquiría, «sin obstáculo ni dificultad que no fuese a éste imputable».

Un elemento muy importante, a nuestro parecer, es que Jorge Bécquer vendió la propiedad de las obras «en la suposición de que era el único heredero abintestato de su citado padre Don Gustavo Adolfo Bécquer, y de sus hermanos y madre». Esto implicaría que su hermano mayor, Gustavo, habría fallecido por tanto con anterioridad al 31 de enero de 1890. Pero esto no concuerda con las informaciones dadas por Carpintero. Aunque éste admite que no son muchas las noticias que, de modo indudable, tenemos de él, sí poseemos — dice-datos concretos de su vida durante el año 1896:

Se hallan en el archivo de Noviercas y se concretan a tres sentencias dictadas contra él por el Juzgado del Distrito del Parque de Barcelona. La primera «por delito frustrado de hurto y consumado de uso público de nombre supuesto». Lleva fecha de 26 de febrero. La segunda «sobre hurto» contra Gregorio Domínguez Bécquer y Esteban, natural de Noviercas, vecino de esta capital, de treinta y dos años (realmente, tenía treinta y cuatro), platero, soltero, instruido. Lleva fecha de 18 de agosto. La tercera y última le presenta de «treinta y tres años, casado y platero». Lleva fecha de 1 de octubre. Las tres del año $1896^{28}$.

Que debe haber algún error o malentendido en estos datos parece evidente, máxime cuando tenemos constancia que en auto judicial de 11 de junio de 1890, dictado por el Juzgado del Distrito del Sur de Madrid, y en concreto por la Escribanía del actuario Don Francisco Cabrero de Frutos:

Se declararon herederos abintestato de Don Gustavo Adolfo Domínguez Bécquer y Bastida a sus hijos legítimos Don Gustavo Adolfo, Don Emilio y Don Jorge Luis Domínguez Bécquer y Esteban, por fallecimiento de D. Emilio a su madre Doña Casta Esteban Navarro, y habiendo fallecido ésta [lo había hecho también sin otorgar testamento] a sus hijos Don Gustavo Adolfo y Don Jorge Luis Domínguez Bécquer y Esteban, y por último, fallecido aquel también a su abuela materna D. ${ }^{a}$ Antonia Navarro de los derechos a él correspondientes» ${ }^{29}$.

${ }^{28}$ CARPINTERO, Heliodoro, op. cit., p. 170. Termina indicando el autor que don Aurelio Celorrio, amigo íntimo y condiscípulo de Jorge, «recordaba que Gregorio Gustavo [...] murió en Madrid, sin poder concretar fecha, ni aproximadamente.»

${ }^{29}$ AHPN, protocolo 37.435. Las cursivas son nuestras. También quedó constancia de esta decisión en todas las obras de Bécquer inscritas en el RPI, a las que, como era preceptivo, se añadió la siguiente observación: «Por testimonio del Auto del Juzgado de primera instancia del Distrito del Sur de esta Capital -28 Junio 1890 - la propiedad de las obras a que se refiere esta inscripción pasa a ser de D. Jorge Luis Bécquer y Esteban y Da Antonia Navarro, declarados herederos legítimos del Autor en 11 de igual mes y año». Así, por ejemplo, en el libro VIII, folio n. ${ }^{\circ} 140$. 
Con anterioridad a la publicación de esta resolución judicial, y después de la firma del contrato con el editor López Bernagosi, parece ser que Jorge Bécquer se traslada, o retorna, a la localidad soriana de Gómara, donde vivía su abuela materna desde que, en 1881, a la edad de sesenta y siete años, hubiese contraído segundas nupcias con un viudo de aquel lugar, Manuel Zoya Marín. Jorge comienza a pedir prestado dinero a su abuelo político, al parecer siguiendo una inveterada costumbre ${ }^{30}$, y cuando en junio se conoce el auto judicial que hemos mencionado, se encuentra ante dos problemas: ha vendido la propiedad literaria de unas obras que no le pertenecían plenamente, quedando en el aire la cifra que pretendía cobrar del editor barcelonés; y debe un dinero al consorte de su abuela, Manuel Zoya, que no está en condiciones de devolver. A partir de aquí, los pasos que se emprenden para solucionar la situación son tortuosos $\mathrm{y}$, aun sin conocer a fondo los fundamentos de Derecho de la época, se diría que en algunos casos rozan la ilegalidad.

Como primera medida, el 22 de julio de 1890 comparecen ante Virgilio Guillén y Andrés, notario de Madrid, de una parte Manuel Zoya Marín, «de cincuenta y ocho años de edad [...], administrador de la Compañía arrendataria de tabacos; y de la otra Don Jorge Bécquer y Esteban, de veinticuatro años, soltero, estudiante, vecinos ambos de Gómara». Y allí declara éste:

Que para cubrir urgentes necesidades que le rodeaban ha recibido del otro compareciente [...] varias cantidades en distintas ocasiones que calcula ascienden aproximadamente a 1.750 pesetas; y no teniendo metálico para abonarlas ha resuelto [...] que cede, renuncia y traspasa sin limitación alguna a favor del ya repetido Don Manuel Zoya Marín todos cuantos derechos y acciones le correspondan o pudieran corresponderle en lo sucesivo, en la propiedad de todas las obras literarias que en prosa y verso escribió su difunto padre Don Gustavo Adolfo Bécquer, extendiéndose también esta cesión a las que resulten inéditas ${ }^{31}$.

Como consecuencia de esta cesión, el señor Zoya Marín quedaba autorizado para cobrar del señor López Bernagosi la cantidad que éste adeudaba por la compra ratificada en Barcelona, es decir, Zoya y Marín hacía «tam-

${ }^{30}$ Antonia Navarro justificaba su nuevo matrimonio alegando incompatibilidades con su hija, Casta Esteban, que se tomó muy mal el casamiento, y también temor «ante las constantes exigencias de dinero, de su hijo - Higinio- y de su nieto Jorge». CARPINTERO, Heliodoro, op. cit., p. 135.

${ }^{31}$ AHPN, protocolo 36.529, folios 363 a 366. Jorge Bécquer cede de forma absoluta los derechos de las obras de su padre... ipor segunda vez! ¿Hasta qué punto es lícito este contrato? En principio debemos suponer que lo es, puesto que en él, además de reconocer que la propiedad es compartida con su abuela Antonia Navarro, «como heredera del difunto Don Gustavo Bécquer y Esteban», menciona también la venta realizada en Barcelona en enero de ese año, y el notario no encuentra objeción alguna para celebrar el nuevo contrato. De todas formas, sería interesante conocer la opinión de los historiadores del Derecho. 
bién suyas cuantas cantidades deba percibir [el vendedor] por cualquier cesión o enajenación que de las mismas obras haya realizado con anterioridad a este acto». El precio de la transacción se fijaba en 1.750 pesetas, la misma cantidad que Jorge Bécquer adeudaba al señor Marín, el cual se declaraba pagado de su crédito.

El siguiente paso fue una declaración suscrita en Madrid a 17 de octubre de 1890 , por la cual «D. Manuel Zoya y Marín y D. ${ }^{a}$ Antonia Navarro, su esposa, se conforman y aceptan como válida la venta que su nieto D. Jorge hizo de las obras de su Sr. Padre a D. Inocente López», y «presentan su entera conformidad a dicha cesión absoluta, a favor del Sr. López, ofreciendo nada reclamarle, pues así es convenido entre los mismos» ${ }^{32}$.

Posteriormente, en enero de 1891, el propio Manuel Zoya Marín se personará en Barcelona, y el 28 de ese mes, de nuevo ante el notario Eusebio Thos y Boushoms, declara que está autorizado para cobrar la cantidad que el señor Inocente López Bernagosi, presente también en el acto, adeuda aún por la compra de las obras literarias de Gustavo Adolfo Bécquer. Liquidado el pago, el señor Marín «en nombre de su esposa así como en calidad de cesionario de Don Jorge Bécquer, expidió carta de pago a favor de D. Inocente López de cinco mil quinientas pesetas, en completa satisfacción del precio aplazado convenido en el contrato de venta, haciendo gracia al comprador de quinientas pesetas en consideración a causas que no es del caso hacer aquí constar» ${ }^{33}$.

Desde este momento, el editor catalán se convertía en el único propietario de todos los trabajos literarios del poeta sevillano. En cuanto a Jorge Bécquer, su prima Julia indicaba que había ido a la guerra de Cuba, donde enfermó y murió desamparado. Carpintero cree posible que estuviera en Cuba, aunque no le parece probable que fuera durante la insurrección (1895-1898), pues entonces estaba ya en la treintena. En todo caso, considera seguro que no murió allí: su amigo Aureliano Celorrio recordaba que Jorge vivía en la localidad de Orán cuando, en 1908, murió su abuela en Soria. «No vino a recoger la herencia, ni se supo más de él» ${ }^{34}$.

\section{FERNANDO FE: PROPIETARIO ABSOLUTO}

A punto de finalizar el año 1893, el 9 de diciembre, se reúnen en Madrid los editores Inocente López Bernagosi y Fernando Fe, y suscriben un contrato mediante el cual el señor Bernagosi «vende absoluta y perpetuamente al señor Don Fernando Fe Gámez la plena propiedad y el derecho de reproducción ilimitado de todas las obras literarias en prosa o verso

\footnotetext{
${ }^{32}$ RPI, libro VIII, folio n. ${ }^{\circ} 140$ vuelto.

${ }^{33}$ AHPN, protocolo 37.435.

${ }^{34}$ CARPINTERO, Heliodoro, op. cit., p. 165.
} 
escritas por Don Gustavo Adolfo Bécquer Bastida» ${ }^{35}$, tanto de las publicadas como de las inéditas que pudiesen aparecer manuscritas en lo sucesivo, sin reservarse nada «de cuanto adquirió de los señores Don Jorge Bécquer y Don Manuel Zoya Marín», y entendiéndose la cesión tanto para España como para el extranjero.

El precio de la venta se fija en $7.958,9$ pesetas $^{36}$, que podrían pagarse en dos plazos iguales que se harían efectivos el 9 de marzo y el 9 de junio de 1894 , sin que durante este periodo el precio de venta devengara interés o rédito alguno.

Fernando Fe se comprometía a descontar al señor López Bernagosi o a sus herederos «el cuarenta por ciento de su precio en todos los pedidos de las obras objeto de este contrato», en cualquiera de las sucesivas ediciones que el señor $\mathrm{Fe}$ o sus sucesores sacasen al mercado.

De este modo, dieciséis años después de su primera publicación de las Obras de Bécquer, Fernando Fe se convertía en propietario absoluto y perpetuo de todos sus trabajos literarios. López Bernagosi, en los casi tres años que había mantenido la propiedad, no nos consta que realizara ninguna edición de esos trabajos, a pesar de que hemos buscado su pista tenazmente. Para nosotros sigue siendo un enigma cuál fue el motivo que llevó a Bernagosi a adquirir la propiedad de unas obras de las que, según parece, no trató de obtener ningún rendimiento editorial directo. Por lo demás, su tiempo había pasado, en septiembre de 1895 moría en Barcelona a los sesenta y seis años de edad. Le sustituyó en los negocios con notable éxito su hijo Antonio López, pero a la muerte de éste, en 1931, la Librería Española desapareció.

Fernando Fe, por el contrario, realizó aún la quinta (1898), sexta (1907) y séptima (1911) edición de las Obras de Gustavo Adolfo Bécquer, antes de su fallecimiento en Madrid en $1914^{37}$. Posteriormente su viuda, bajo la razón social «Librería de Fernando Fe», puso en venta cuatro ediciones más: la octava (1915), novena (1922), décima (1924) y undécima (1928) ${ }^{38}$. Así, de algún modo resultaban finalmente verídicas las palabras de Julia Bécquer: Fernando Fe y sus herederos ganaron, en efecto, bastante dinero con las publicaciones de su tío, mientras los hijos de éste llevaron sólo una vida humilde y, al parecer, funesta. Pero el proceso que llevó a esta situación fue, sin embargo, muy distinto de como Julia nos lo había contado.

\footnotetext{
35 AHPN, protocolo 37.435, folios 5.325 a 5.333 .

${ }^{36}$ López Bernagosi ganaba, sobre el precio total al que las había adquirido, 1.708,9 pesetas.

${ }^{37}$ La quinta y la sexta aparecieron conjuntamente en Madrid y Sevilla, donde el librero tenía sucursal. La quinta contaba con una nueva adición, el poema «A todos los santos». Las demás ya no sufrieron añadido alguno. Vid. SCHNEIDER, Franz, op. cit., pp. 391-392.

${ }^{38}$ Esta es la última con el sello de los sucesores de Fernando Fe. A partir del año 1934 será el editor Manuel Aguilar quien comience a editar unas denominadas Obras completas
} 


\section{CONCLUSIONES}

El artículo pone de manifiesto cómo la investigación archivística, la vuelta a las fuentes documentales, es imprescindible para reconstruir las condiciones del campo literario, ayudándonos a discernir y, en este caso concreto, a desmontar inercias historiográficas basadas en la repetición de datos que no han sido suficientemente contrastados, por carecer del apoyo documental preciso. Pero cuando los estudios de toda índole sobre Gustavo Adolfo Bécquer han proliferado tanto, no resulta fácil encontrar nuevas fuentes que puedan arrojar más datos sobre el poeta.

En nuestro caso, los tareas de investigación sobre la Ley de Propiedad Intelectual de 1879 y su repercusión en el mercado editorial del momento, un tema muy poco abordado aún, nos han puesto sobre la pista de esta serie de contratos, y con ello se nos han revelado buena parte de las vicisitudes a que se vieron sometidas las obras de Bécquer.

Como resultado, nos parece bastante evidente que Gustavo, hijo del poeta - un joven de tan sólo quince años cuando Fernando Fe editó por primera vez las Obras de su padre-, no vendió la propiedad de las mismas al editor, como afirmó Julia, o cuando menos, si queremos dejar un cortés margen a la duda, no lo hizo en ningún caso de forma absoluta y perpetua. Esto sólo ocurrió años después, en 1890, y la responsabilidad de esa cesión corresponde a Jorge Bécquer y a su abuela materna, Antonia Navarro. Fernando Fe no se hizo dueño absoluto de esa propiedad hasta 1893, y ello después de invertir, a buen seguro, más dinero que esas cerca de 13.000 pesetas que suman en total las operaciones comerciales de las que hemos dado cuenta aquí.

La información que proporcionamos sobre la biografía de los hijos de Bécquer aporta también algunos datos relevantes. Aclara, por ejemplo, el motivo del «etéreo» paso por el mundo del hijo menor, Emilio, el cual, según declaración de su madre Casta Esteban en documento notarial, habría fallecido en 1878, es decir, a los nueve o diez años de edad. En cuanto al hijo mayor, Gustavo, las noticias son sorprendentes. No podemos explicarnos cómo, si se le declara fallecido en un auto judicial de junio de 1890 , pueden luego los juzgados de Barcelona dictar tres sentencias contra él en el año 1896. Literalmente, reaparece después de muerto, como escapado

de Bécquer. Sin embargo, la Ley de Propiedad Intelectual de 1879, entonces vigente, extendía hasta ochenta años los derechos de autor post mortem, lo que significaba que hasta 1950 los trabajos literarios de Bécquer no entrarían en el dominio público. Esto parece sugerir que existió al menos una nueva venta de las obras, por la cual Manuel Aguilar habría adquirido los derechos.

${ }^{39}$ Vid. BLANQUAT, Josette; BOTREL, Jean-François (eds.). Clarín y sus editores. 65 cartas inéditas de Leopoldo Alas a Fernando Fe y Manuel Fernández Lasanta 1884-1893. Rennes: Université de Hauge-Bretagne, 1981, p. 9, nota al pie. 
del Monte de las ánimas, y para inflamar aún más las imaginaciones más novelescas, su primera aparición se produce precisamente bajo «nombre supuesto». También conocemos ahora algunas de las andanzas de su hermano Jorge durante el año 1890, incluyendo su llamativa relación con el editor republicano y catalanista López Bernagosi. Las motivaciones que tuvo éste para comprar la propiedad literaria de las obras de Bécquer nos resultan inciertas, pues sorprende que no diera a las prensas alguno de esos trabajos. Cuando menos, quedamos a la espera de descubrirlo.

Nos gustaría finalizar con unas breves palabras de desagravio para la figura del editor Fernando Fe. De su relevante papel editorial en el periodo de la Restauración da buena cuenta la nómina de escritores a los que publicó: Clarín, Valera, Pardo Bazán, Baroja, Víctor Hugo, Rudyard Kipling... y una larga lista de primeras figuras, tanto nacionales como extranjeras. Pero además convirtió su librería de la Carrera de San Jerónimo en un cenáculo literario al que asistían con regularidad las plumas más destacadas de Madrid, revitalizando así la vida cultural en la capital. No obstante, las relaciones con los autores no siempre fueron fáciles, y si escritores como Valera o Pereda le tildaron ya en su tiempo de «roñoso» ${ }^{39}$, este calificativo se ha ensombrecido luego con las más negras tintas de la usura, siempre que se ha mencionado su nombre en relación con la explotación comercial de las obras de Gustavo Adolfo Bécquer. Todavía es muy fuerte en nosotros la imagen romántica del escritor bohemio y pobre, explotado por empresarios sin escrúpulos. Seguramente por eso, en 1922, en una conferencia pronunciada en Barcelona, Rafael Calleja anunciaba a su auditorio que estaban ante un caso «insólito, insospechado, absolutamente original», porque «voy públicamente a hablar bien del editor» ${ }^{40}$. No ha sido este nuestro caso, no hemos pretendido hablar bien ni mal de la figura del editor. Simplemente consideramos que, allá donde sea posible, parece conveniente otorgar al César lo que es del César.

Fecha de recepción: 30 de septiembre de 2008

Fecha de aceptación: 3 de marzo de 2009

${ }^{40}$ CALLEJA, Rafael. El editor. Conferencia de la serie organizada por la Cámara Oficial del Libro en la Feria de Muestras de Barcelona en marzo de 1922. Madrid: Editorial Saturnino Calleja S. A., 1922, p. 21. 
